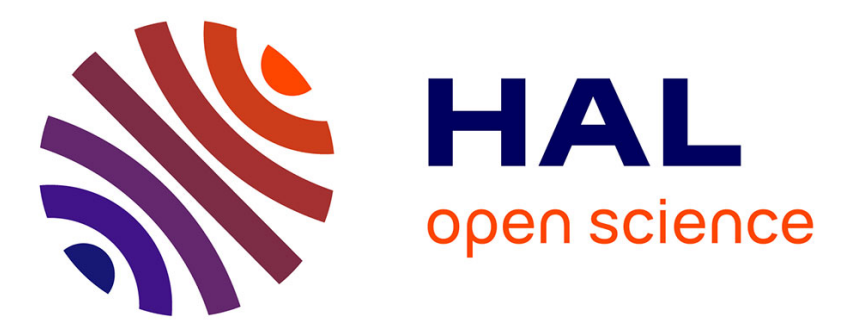

\title{
Conformational studies of bipyrimidine-based mesogens by combination of DFT calculations and temperature-dependent infrared studies
}

B. Barszcz, A. Bogucki, R. Świetlik, H. Akdas-Kiliç, F. Camerel, T. Roisnel

\section{- To cite this version:}

B. Barszcz, A. Bogucki, R. Świetlik, H. Akdas-Kiliç, F. Camerel, et al.. Conformational studies of bipyrimidine-based mesogens by combination of DFT calculations and temperature-dependent infrared studies. Liquid Crystals, 2019, 46 (9), pp.1403-1414. 10.1080/02678292.2019.1575990 hal-02051167

HAL Id: hal-02051167

https://hal-univ-rennes1.archives-ouvertes.fr/hal-02051167

Submitted on 22 Mar 2019

HAL is a multi-disciplinary open access archive for the deposit and dissemination of scientific research documents, whether they are published or not. The documents may come from teaching and research institutions in France or abroad, or from public or private research centers.
L'archive ouverte pluridisciplinaire HAL, est destinée au dépôt et à la diffusion de documents scientifiques de niveau recherche, publiés ou non, émanant des établissements d'enseignement et de recherche français ou étrangers, des laboratoires publics ou privés. 


\title{
Conformational studies of bipyrimidine based mesogens by combination of DFT calculations and temperature-dependent infrared studies
}

\author{
Bolesław Barszcz ${ }^{1}$, Andrzej Bogucki ${ }^{1}$, Roman Świetlik ${ }^{1, *}$, \\ Huriye Akdas-Kiliç̌ ${ }^{2}$ Franck Camerel ${ }^{2, *}$, and Thierry Roisnel ${ }^{2}$ \\ ${ }^{1}$ Institute of Molecular Physics, Polish Academy of Sciences, Mariana Smoluchowskiego 17, \\ 60-179 Poznań, Poland. \\ ${ }^{2}$ Univ. Rennes, CNRS, ISCR - UMR 6226, F-35000 Rennes, France. \\ Email:swietlik@ifmpan.poznan.pl, Franck.camerel@univ-rennes1.fr
}

Keywords: Bipyrimidine, Liquid crystal, Dihedral angle, Temperature-dependent IR studies, DFT calculations,

\begin{abstract}
Combination of DFT calculations and solid-state temperature-dependent infrared spectroscopy have confirmed that the central core of recently developed bipyrimidine based mesogens is not flat, i.e. do not adopt a disk shape, inside the columnar liquid crystalline phase. For this purpose the intensities and the frequency shifts of the most sensitive $\mathrm{C}-\mathrm{N}$ and $\mathrm{C}-\mathrm{C}$ bands of the central bipyrimidine core have been studied as a function of the temperature and of the dihedral angle. The results support the reported packing model in which the molecules are interdigitated alternatively along their long axis and their short axis to form columns inside the mesophase.
\end{abstract}




\section{Introduction}

Supramolecular chemistry [1], in which molecules self-assemble into complex architectures in solid state or in solution, is govern by the extent and the directionality of the intermolecular interactions but also in a first instance by the shape of the molecule. This latest point is far the less important, especially in the field of liquid crystalline materials [2]. Rod-like molecules will preferentially organize into nematic $(\mathrm{N})$ or smectic $(\mathrm{Sm})$ phases whereas molecules, built around discoid core, will have the tendency to pile up to form columnar phases [3]. The columns formed by the stacking of the discs can organize into 2D lattices: hexagonal lattice $\left(\mathrm{Col}_{h}\right)$, rectangular lattice $\left(\mathrm{Col}_{\mathrm{r}}\right)$, and oblique lattice $\left(\mathrm{Col}_{\mathrm{ob}}\right)$. The columnar phase of hexagonal symmetry being certainly the most frequently encountered phase with disc-like molecules. Other core geometry, such as sphere [4-6], cube [7], or cross [8-9] can be used but their packing is far more difficult to achieve without appropriate functionalization strategies and often leads to more exotic molecular packing schemes.

Recently, we have demonstrated that, by a rational design strategy, NLO-phores of D2d symmetry based on donor-substituted styryl bipyrimidine core carrying long carbon chains can also be organized into liquid crystalline materials [10]. The BPM-3,4-Cn compounds with $\mathrm{n}=$ 12, 16 were found to be mesomorphic (Scheme 1). BPM-3,4-C16 form a columnar mesophase of hexagonal symmetry $\left(\mathrm{Col}_{h}\right)$ over a wide temperature range from $35{ }^{\circ} \mathrm{C}$ up to $125{ }^{\circ} \mathrm{C}$. The mesomorphism of BPM-3,4-C12 compound was found to be richer with the formation of $\mathrm{Col}_{\text {hex }}$ phase at high temperatures between $95^{\circ} \mathrm{C}$ and $123^{\circ} \mathrm{C}$ and of a lamello-columnar mesophase of rectangular symmetry (LamCol rec) phase between $95{ }^{\circ} \mathrm{C}$ and $70{ }^{\circ} \mathrm{C}$. Based on the crystal structure of a related compound, a packing model was proposed in which the molecules are interdigitated alternatively along their long axis and their short axis to form columns. In this packing model, the bipyrimidine core adopt pseudo-tetrahedral octupolar symmetry and the bipyrimidines aromatic cycles have a non-zero dihedral angle, giving the molecules a twisted cross conformation. Such molecular packing was also proposed more recently for the stacking of bipyrimidine molecules, carrying chiral carbon chains, into flexible and noncentrosymmetric organic liquid crystalline thin films [11]. 


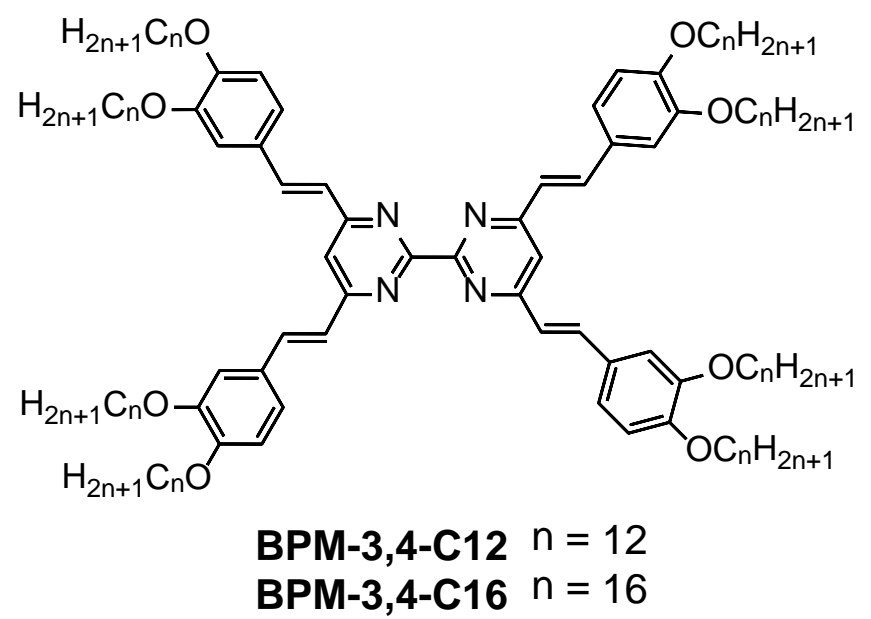

Scheme 1. Molecular structure of the chiral BPM compounds.

However, the two pyrimidine fragments of the bipyrimidine core can easily rotate around the central C-C bond to adopt a flat geometry (Figure 1). In fact, the crystalline structure of the related compound, carrying methyl groups in place of the long carbon chains have shown that, in presence of methanol molecules, the bipyrimidine core can adopt a completely flat conformation (dihedral angle $=180.000(141)^{\circ}$ ). The energy stabilization due to the hydrogen bonding between the two pyrimidine fragments and the solvent molecule can overcome the repulsions of the lone pairs between the nitrogen atoms of the two pyrimidine fragments. But, in the condensed liquid crystalline phase, the formation of a disk-like molecule could not be properly ruled out during the elaboration of the packing model discussed above. In addition, a flat discoid-like conformation of molecular core would have more easily explained the formation of a columnar mesophase. 


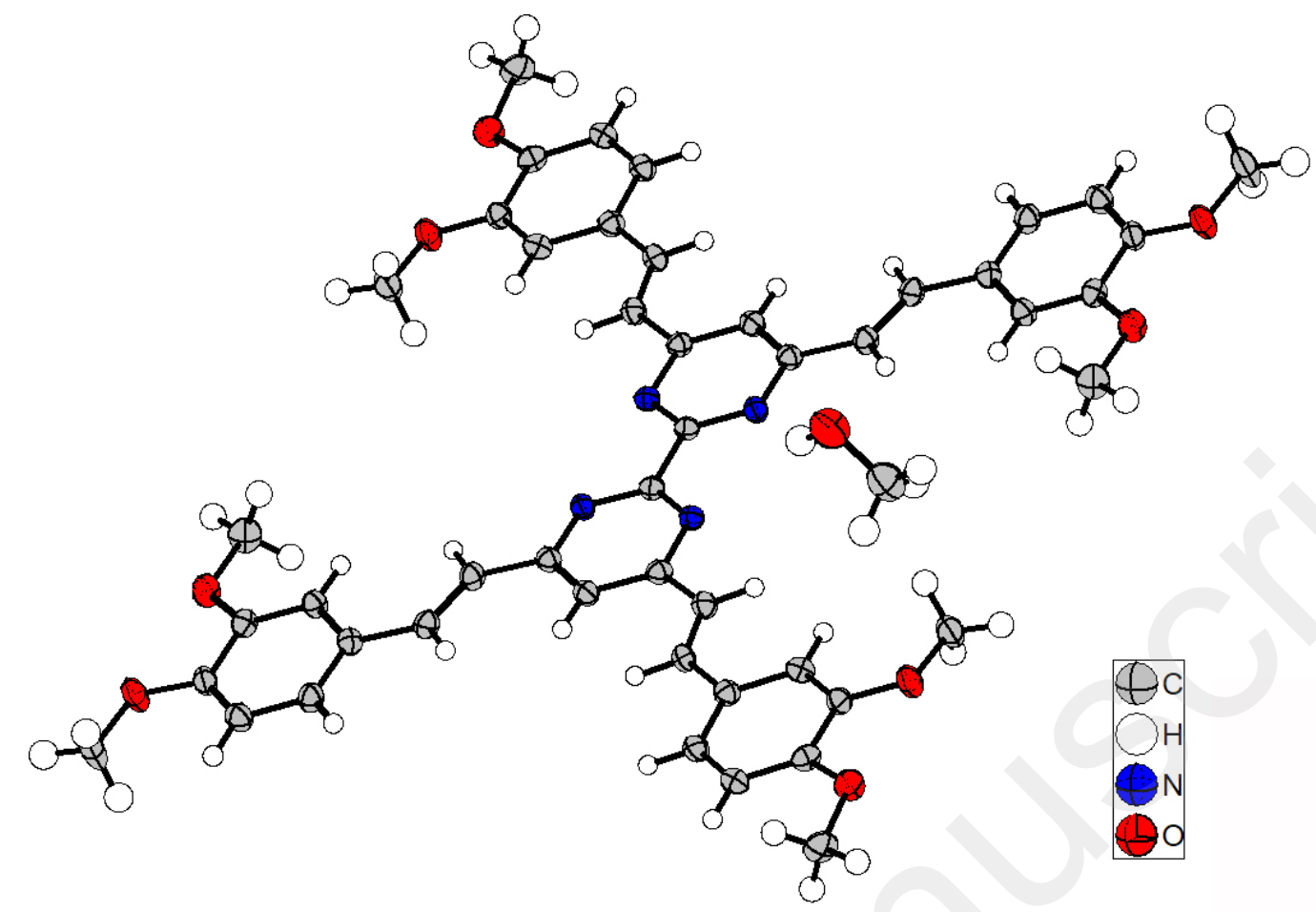

Figure 1. ORTEP view of BPM-3,4-C1 compound crystallized in presence of methanol molecules ( $\mathrm{n}=1$ ) (monoclinic, $\mathrm{P} 21 / \mathrm{a}, \mathrm{a}=17.3673(7) \AA, \mathrm{b}=7.4860(4) \AA, \mathrm{c}=17.5622(7) \AA, \beta$ $\left.=99.972(2)^{\circ}, \mathrm{Z}=2\right)(\mathrm{CCDC} 1585239)$.

In order to get more insight about the molecular conformation of the bipyrimidine core inside the columnar liquid crystalline phases and to confirm that the molecule do not adopt a flat conformation, DFT calculations and temperature-dependent infrared spectroscopy experiments were performed on the BPM-3,4-Cn $(n=12,16)$ compounds. In fact, the vibrations of the central C-C bond of the bipyrimidine core should be highly sensitive to the dihedral angle between the two pyrimidine fragments. Thus, it should be possible to correlate the position of the vibration bands of the central C-C bond directly to the conformation of the molecule.

In the present work, DFT calculations were performed as a function of the dihedral angle of the bipyrimidine core and the IR vibrational spectra were simulated for each configuration. The vibrational bands were properly assigned and the band related to CN and CC stretching in molecular core (perpendicular to the central bond) at $1605 \mathrm{~cm}^{-1}$ was found to be sensitive to the dihedral angle of the bipyrimidine core. Then, studies of the position of this band in the experimental temperature-dependent IR spectra of BPM-3,4-Cn compounds $(n=12,16)$ has allowed to estimate the dihedral angle in the various phases and to confirm that the bipyrimidine core adopt a twisted cross conformation in the liquid crystalline phase as initially proposed in the molecular packing model. 


\section{Experimental part}

BPM-3,4-Cn compounds with $n=1,12,16$ have been prepared as previously reported [10]. The single crystal X-ray structure of BPM-3,4-C1 was recorded on a APEXII Bruker-AXS diffractometer equipped with a CCD camera and a graphite-monochromated Mo Ka radiation source $(\lambda=0.71073 \AA$ ) at 150 (2) $\mathrm{K}$ (Centre de diffractométrie X, Université de Rennes 1 , France). Single crystals suitable for X-ray diffraction have been obtained by slow evaporation of a solution of BPM-3,4-C1 in a methanol/dichloromethane mixture. Bruker SMART program were used to refine the values of the cell parameters. Data reduction and correction for absorption (SADABS) were carried out using the Bruker SAINT programs. 5080 unique reflections were obtained from a total of 19238 measured reflections (Rint $=0.0462$ ), in the range of h: -20 to 22; $\mathrm{k}$ : -9 to 9; $\mathrm{l}:-22$ to 20 with $\theta \max =27.482^{\circ}$. The structure was solved by direct methods using the SIR97 program and then refined with full-matrix least-square methods based on F2 (SHELX-97) with the aid of the WINGX program. Convergence for 297 variable parameters by least-squares refinement on $\mathrm{F} 2$ with $\mathrm{w}=1 /\left[\sigma^{2}\left(\mathrm{Fo}^{2}\right)+(0.1035 \mathrm{P})^{2}+0.0000 \mathrm{P}\right]$, where $\mathrm{P}=\left(\mathrm{Fo}^{2}+2 \mathrm{Fc}^{2}\right) / 3$ for 3145 reflections with $\mathrm{I}>2 \sigma(\mathrm{I})$ was reached at $\mathrm{R}=0.0463$ and wR $=0.0979$ with a goodness-of-fit of 1.014. The final difference Fourier map was featureless, with maximum positive and negative peaks of 0.236 and -0.209 e $\AA^{-3}$ respectively. All non-hydrogen atoms were refined with anisotropic atomic displacement parameters. The $\mathrm{H}$ atoms were finally included in their calculated positions. Crystallographic data for structural analysis of BPM-3,4C1 have been deposited with the Cambridge Crystallographic Data Centre under CCDC No 1585239. Copies of this information may be obtained free of charge from the web site www.ccdc.cam.ac.uk.

Infrared absorption spectra were studied within the mid-IR range $\left(400-4000 \mathrm{~cm}^{-1}\right)$ by using Bruker Equinox 55 FT-IR spectrometer equipped with a $\mathrm{KBr}$ beam splitter. For temperature measurements the samples were placed on a KBr plate in THMS 600 Linkam heating stage equipped with a temperature controller. At the beginning, the solid state samples in the form of single crystal or powder were measured at room temperature. Subsequently, they were heated until melting to obtain thin films which were cooled down and heated again. Each temperature cycle was done between room temperature and temperature above melting point and the IR spectra were permanently collected. Before each measurement the sample temperature was stabilized for several minutes.

We observed melting of BPM-3,4-C16 into the liquid crystalline phase at about $63{ }^{\circ} \mathrm{C}$ and at about $79^{\circ} \mathrm{C}$ for BPM-3,4-C12. It is to be mentioned that previous investigations showed 
that in both samples the phase transitions from the crystal to liquid crystal state undergo at 60$70^{\circ} \mathrm{C}$

\section{DFT calculations}

In order to assign vibrational bands and identify bands especially sensitive to twisting of the molecules suitable DFT calculations were performed using Gaussian program [12]. All calculations were mostly made using B3LYP hybrid functional with 6-31G(d,p) basis set. At the beginning, we calculated the energy of the simplified molecular core for various dihedral angles (Fig. 2) - it is seen that the energy minimum is not observed for the flat geometry (dihedral angle equals to $0 \mathrm{deg}$ ).

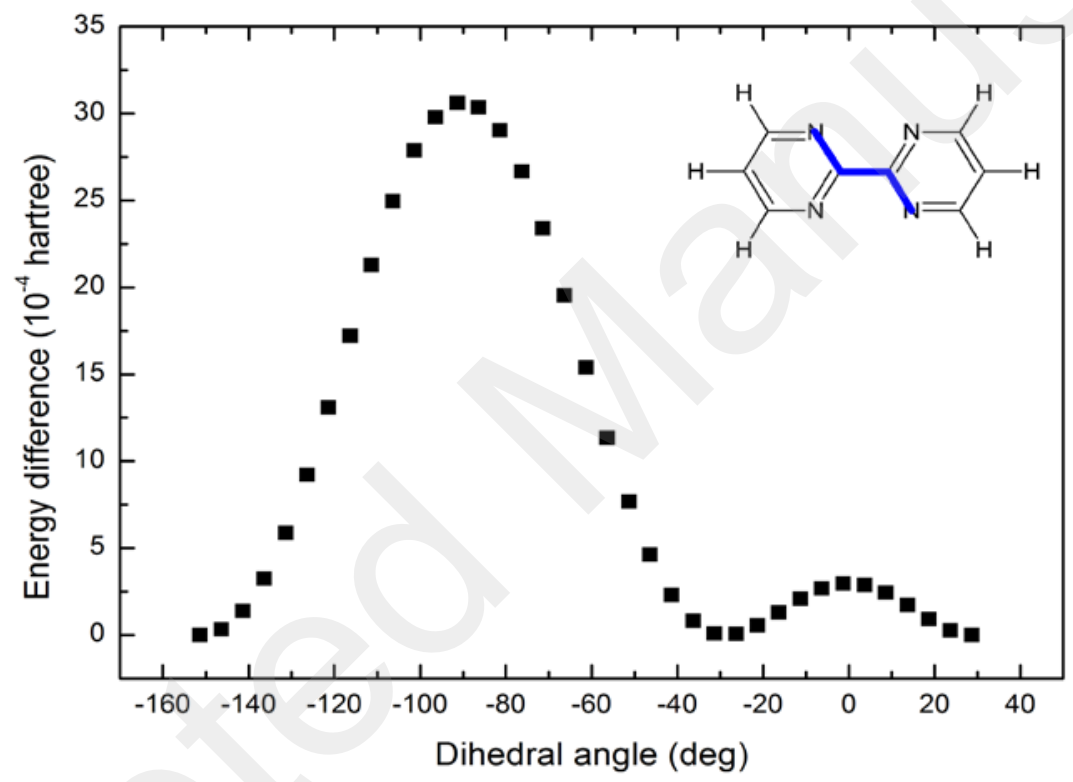

Figure 2. Total energy as a function of dihedral angle (the dihedral angle equals to $0^{\circ}$ for the flat molecule).

Subsequently, vibrational spectra of molecular core with a dihedral angle of $30^{\circ}$ (minimum energy) were calculated and assigned (Fig. 3). Bands related to $\mathrm{CN}$ stretching vibration are especially important because they are expected to be sensitive to detect the twisting of the molecule. As seen in Fig. 3, the calculated bands assigned to in-plane CC and CN stretching perpendicular to the long axis are observed at 1605, $1628 \mathrm{~cm}^{-1}$. Two additional bands assigned to in-plane CN stretching along the long axis of the molecule are also observed at about 1173 , $1450 \mathrm{~cm}^{-1}$. The doublet 1605 and $1628 \mathrm{~cm}^{-1}$ exhibits substantial modifications when the dihedral angle is changed (Fig. 4). 


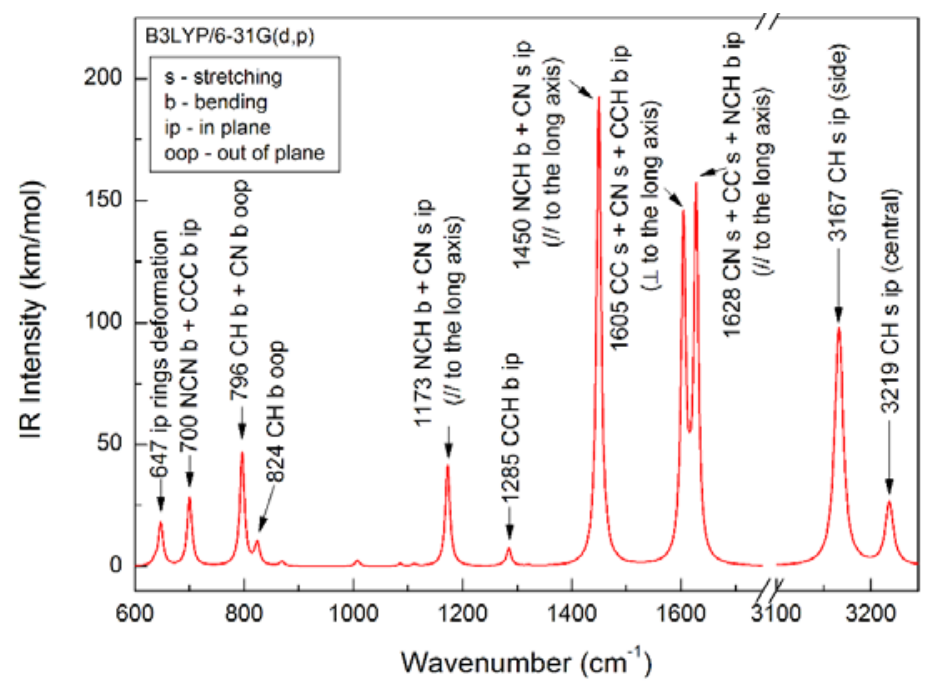

Figure 3. Calculated IR spectra of the molecular core.

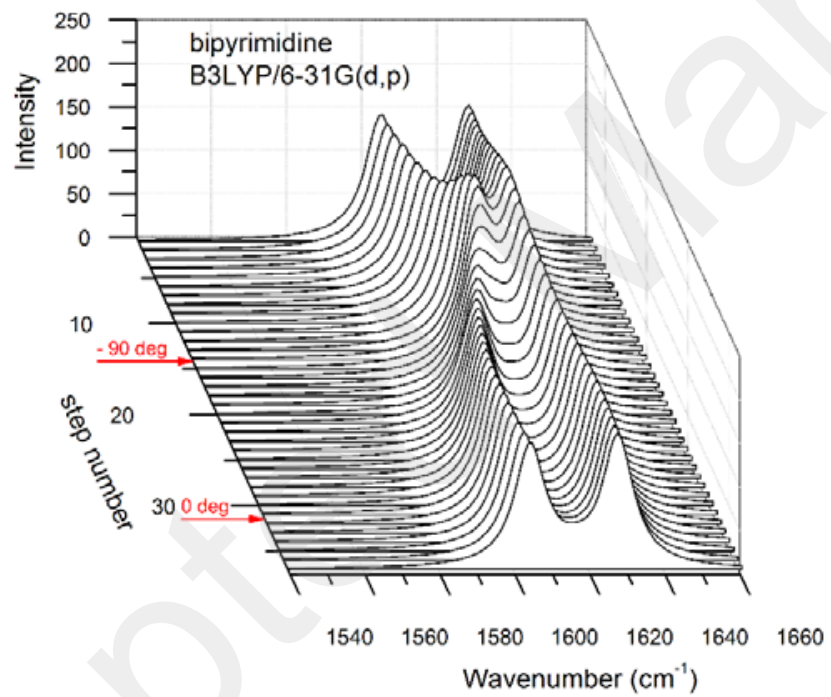

Figure 4. Vibrational band of the molecular core related to CN and CC stretching as a function of dihedral angle.

In the next step, calculations for an extended molecular core, i.e. molecule BPM-3,4-C1 were done. The BPM-3,4-C1 is equivalent to BPM-3,4-C16 and BPM-3,4-C12 molecules without aliphatic chains (Fig.1). The simulated molecules were prepared using crystallographic data of a parent compound carrying $\mathrm{NEt}_{2}$ groups in the 4 position of the peripheral phenyl fragments (CCDC 707590) [13]. The $\mathrm{NEt}_{2}$ groups were removed and replaced by methoxy groups in the 3 and 4 position. Like this, the alkyl chains were limited to one $\mathrm{CH}_{3}$ group for simplicity. Such simplification is justified because the length of the alkyl chains affects mainly the ability to self-organization and their influence on the spectral properties is relatively small 
[14]. The crystallographic data are available for two molecules: A and B with starting dihedral angles $73^{\circ}$ and $36^{\circ}$, respectively. At the beginning these molecules were optimized as isolated species without any restrictions on dihedral angle. The result gave equilibrium geometry with dihedral angle $16^{\circ}$ (total energy: -2677.54692 hartree, dipole moment: 6.6215 Debye) for A molecule and $32^{\circ}$ (total energy: -2677.5305 hartree, dipole moment: 3.2415 Debye) for B molecule. Because of the lower total energy, the A molecule was used for the calculations of the vibrational spectra at specific dihedral angles. The calculations were performed for dihedral angles from $0^{\circ}$ to $90^{\circ}$ with $15^{\circ}$ steps. For each calculation the dihedral angle was set to a specific value and frozen. The geometry of the remaining part of the molecule was optimized and the normal modes calculations were performed for such optimized structure. Table 1 summarizes the values of total energy and dipole moment calculated at various dihedral angles while Fig. 5 presents the equilibrium geometry for the $15^{\circ}$ case.

Table 1. The calculated total energies and dipole moments of BPM-3,4-C1.

\begin{tabular}{|c|c|c|}
\hline $\begin{array}{l}\text { Dihedral angle } \\
\text { (deg) }\end{array}$ & Total energy (hartree)* & Dipole moment (Debye) \\
\hline 0 & -2677.5455 & 6.44 \\
15 & -2677.5469 & 6.59 \\
\hline 30 & -2677.5457 & 6.44 \\
\hline 45 & -2677.5443 & 6.12 \\
\hline 60 & -2677.5430 & 6.31 \\
\hline 75 & -2677.5395 & 4.66 \\
\hline 90 & -2677.5389 & 4.37 \\
\hline
\end{tabular}

* 1 hartree is $27.2116 \mathrm{eV}$

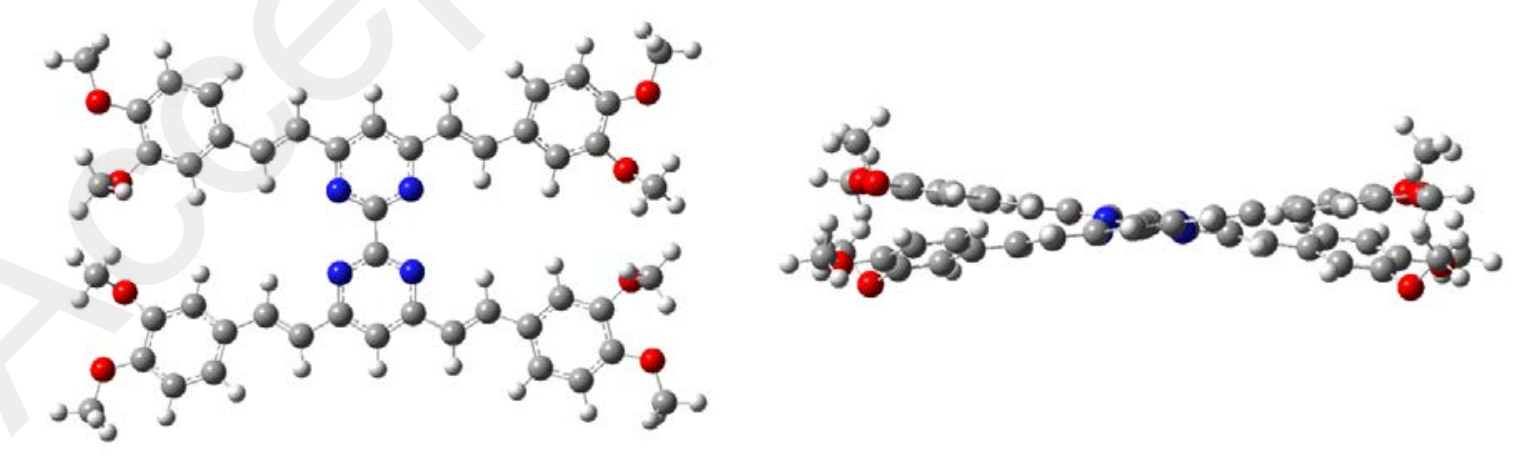

Figure 5. The equilibrium geometry of BPM-3,4-C1 molecule with dihedral angle frozen at $15^{\circ}$. 
The lowest total energy (i.e. the highest stability) was obtained for the $15^{\circ}$ (Fig. 5), which is quite obvious since this value is closest to the $16^{\circ}$ geometry obtained in the previous calculations without restrictions on dihedral angle. The dipole moment is the highest for this case and decreases when the dihedral angle is changed. The differences between the total energy values are up to 0.007972 hartree $(0.21 \mathrm{eV})$ between $15^{\circ}$ and $90^{\circ}$ geometries. However the differences between neighboring steps are smaller (for example between $0^{\circ}$ and $15^{\circ}$ it is only 0.001403 hartree $(0.038 \mathrm{eV}))$ and comparable with the $\mathrm{kT}$ energy $(0.026 \mathrm{eV}$ at $300 \mathrm{~K}$ and 0.035 $\mathrm{eV}$ at $400 \mathrm{~K})$. The simulated infrared spectra for various dihedral angles are presented in Fig 6.

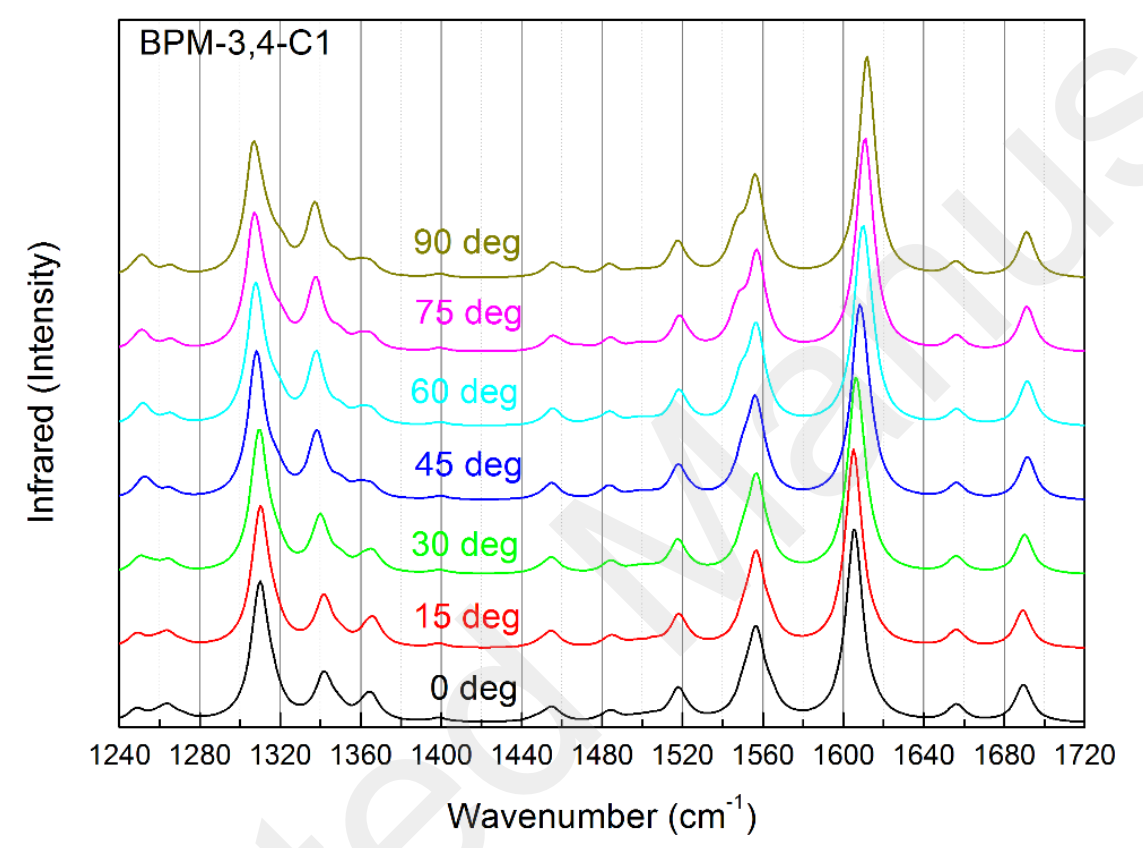

Figure 6. The simulated IR spectra of BPM-3,4-C1

The most distinct changes are observed for the band related to CN and CC stretching in molecular core (perpendicular to the central bond), which is observed at $1605 \mathrm{~cm}^{-1}$ for the dihedral angle $0^{\circ}$ and shifts to $1612 \mathrm{~cm}^{-1}$ for the dihedral angle $90^{\circ}$. The position of band at $1557 \mathrm{~cm}^{-1}$ does not change because it is related to the CC stretching and $\mathrm{CCH}$ bending vibrations in benzene rings and it does not involve the central core of the molecule. However, at about $1551 \mathrm{~cm}^{-1}$, there is a small component of this band related to the out-of-plane deformation of the central core which significantly increases its intensity with the change of dihedral angle. This band is also Raman active, so its evolution is visible better in Raman spectra presented in Fig. S1 (ESI). 
Another IR band sensitive to the rotation of the central part is the stretching of $\mathrm{CN}$ (core) and CC (benzene rings) bonds (with CCH bending) observed at $1310 \mathrm{~cm}^{-1}$ for $0^{\circ}$, which on twisting shifts to $1307 \mathrm{~cm}^{-1}$ for $90^{\circ}$. Detailed positions of these bands are gathered in Table 2 .

Table 2. Selected vibrational bands calculated for BPM-3,4-C1 (wavenumbers in $\mathrm{cm}^{-1}$ ). Infrared Intensities (in $\mathrm{km} / \mathrm{mol}$ ) are given in parenthesis.

\begin{tabular}{|l|l|l|l|l|}
\hline \multirow{2}{*}{$\begin{array}{c}\text { Dihedral angle } \\
\text { (deg) }\end{array}$} & $\begin{array}{c}\text { CN s + CC s } \\
\text { (center) }\end{array}$ & $\begin{array}{c}\text { CC s + CCH b } \\
\text { (benzene rings) }\end{array}$ & $\begin{array}{c}\text { oop deformation } \\
\text { (center + benzene } \\
\text { rings) }\end{array}$ & $\begin{array}{c}\text { CCH b + CN s + } \\
\text { CC s + oop } \\
\text { deformation } \\
0\end{array}$ \\
\hline 15 & $1605(2607)$ & $1557(989)$ & $1551(287)$ & $1310(1624)$ \\
\hline 30 & $1605(2649)$ & $1557(1095)$ & $1551(257)$ & $1310(1719)$ \\
\hline 45 & $1606(2568)$ & $1557(1058)$ & $1551(318)$ & $1310(1714)$ \\
60 & $1608(2375)$ & $1556(1014)$ & $1550(416)$ & $1308(1570)$ \\
\hline 75 & $1609(2124)$ & $1557(869)$ & $1549(471)$ & $1307(1230)$ \\
\hline 90 & $1610(1848)$ & $1557(770)$ & $1548(501)$ & $1307(1021)$ \\
\hline
\end{tabular}

* s - stretching, b - bending, ip - in plane, oop - out of plane

All the given wavenumbers were unscaled. Usually, the calculated wavenumbers are higher than experimentally observed bands positions because of the approximations used during calculations (isolated molecule, harmonic vibrations). To improve the agreement between the experimental and calculated data and make the interpretation easier, it is possible to use appropriate scaling factors [15]. The effect is shown in Fig. S2 (ESI) were the experimental infrared spectrum is compared with calculated ones.

Experimental IR spectra of thin films of both compounds at room temperature are displayed in Fig. 7. In Table 3 most prominent bands in experimental IR spectra are collected and compared with the results of DFT calculations. 


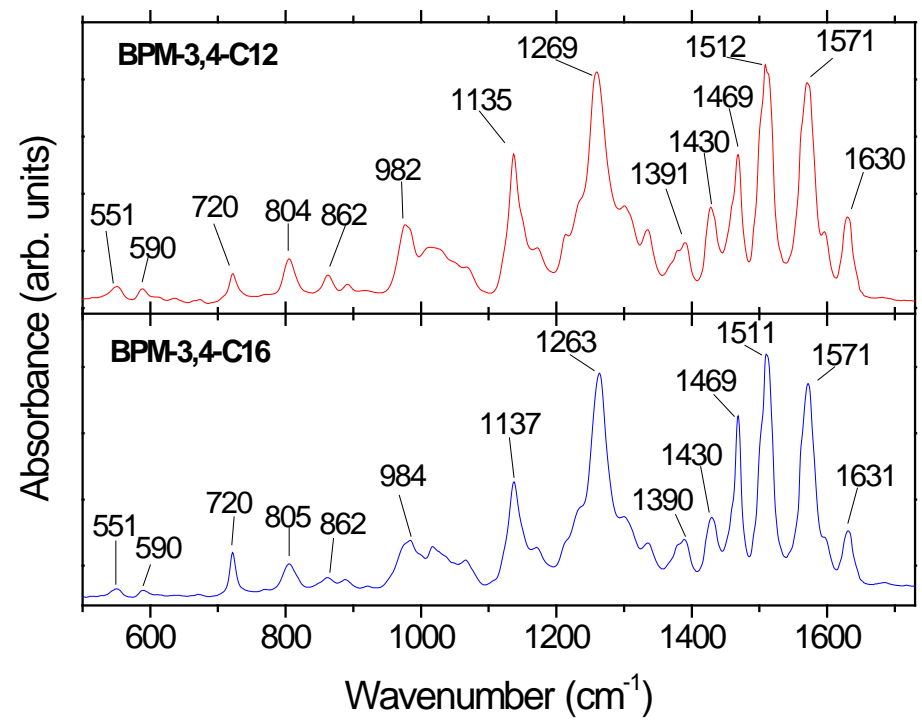

Figure 7. Room temperature infrared spectra of thin films of BPM-3,4-C12 and BPM-3,4-C16.

Table 3. Most prominent vibrational bands observed for BPM-3,4-C12 and BPM-3,4-C16 in the form of thin films at room temperature together with DFT calculated values and approximate description. Note that calculations were performed for simplified version of the molecule (see text for details).

\begin{tabular}{|c|c|c|c|c|}
\hline \multicolumn{2}{|c|}{ Experiment $\left(\mathrm{cm}^{-1}\right)$} & \multicolumn{2}{|c|}{ Calculations $\left(\mathrm{cm}^{-1}\right)$} & \multirow{2}{*}{ Approximate description** } \\
\hline C12 & C16 & unscaled & scaled* & \\
\hline 1630 & 1631 & 1689 & 1624 & $\mathrm{C}=\mathrm{C}$ s (chains) \\
\hline 1571 & $\mid 1571$ & 1605 & 1543 & CN s + CC s (center) \\
\hline 1512 & 1511 & $\begin{array}{l}1557 \\
1551\end{array}$ & $\begin{array}{l}1497 \\
1491\end{array}$ & $\begin{array}{l}\text { CC s + CCH b (benzene rings) } \\
\text { oop deformation (center + benzene rings) }\end{array}$ \\
\hline 1469 & 1469 & 1518 & 1459 & $\mathrm{CH}_{3} \mathrm{~b}$ \\
\hline 1335 & 1335 & 1367 & 1314 & $\mathrm{CCH} \mathrm{b}$ (chains) + CC s (benzene rings) \\
\hline 1300 & 1300 & 1342 & 1290 & $\mathrm{CCH} \mathrm{b}+\mathrm{CN}$ s + CC s + oop deformation \\
\hline 1269 & 1263 & $\mid 1310$ & 1259 & $\mathrm{CCH} \mathrm{b}+\mathrm{CN}$ s $+\mathrm{CC} \mathrm{s}+$ oop deformation \\
\hline 1135 & 1137 & 1155 & 1110 & $\mathrm{CCH}$ b oop (benzene rings) $+\mathrm{CCH} b$ ip \\
\hline
\end{tabular}

* scaling factor: 0.9614

** $\mathrm{s}$ - stretching, b - bending, ip - in plane, oop - out of plane

Shortly summarizing the calculation results, the IR spectra are affected by the change of the dihedral angle. The influence can be observed as a small shifts of bands position and/or changes of their intensities. We have chosen only a few bands described above to identify the 
changes, because those bands are most prominent in experimental spectra. The changes can be notified also in the case of other vibrational bands, however they are not so clear and distinct.

\section{Temperature dependence of IR spectra and discussion}

For each sample we studied temperature dependence of IR spectra in three steps: (1) the crystalline sample was put on a $\mathrm{KBr}$ plate and heated up until melting into the isotropic fluid phase as a thin layer; (2) then the obtained thin layer was cooled down to room temperature; (3) finally, the thin layer was heated again until melting into the isotropic phase. During temperature cycles modifications of the IR spectra were observed and analyzed, focusing on the region of the CC and CN stretching modes, which should be sensitive to twisting of molecules, as suggested by calculations

\section{(a) Thin film formation (step 1)}

For BPM-3,4-C16 crystals at $24^{\circ} \mathrm{C}$ we see a band at $1577 \mathrm{~cm}^{-1}$ with a side-band at 1562 $\mathrm{cm}^{-1}$ (Fig. 8 - right panel) which is assigned to $\mathrm{CN}$ and $\mathrm{CC}$ stretching. On temperature increasing the relative intensity of the $1562 \mathrm{~cm}^{-1}$ peak grows but without any visible substantial frequency shift, while the frequency of the $1577 \mathrm{~cm}^{-1}$ peak slightly decreases reaching about $1570 \mathrm{~cm}^{-1}$ above $90{ }^{\circ} \mathrm{C}$. In temperature range $60-70{ }^{\circ} \mathrm{C}$ we see a change of the doublet shape mostly due to the intensity increase of the $1562 \mathrm{~cm}^{-1}$ peak.

We also investigated temperature dependence of the integral intensity of the sum of both peaks. As seen in Fig. 9a above about $65{ }^{\circ} \mathrm{C}$ begins a significant increase of the integral intensity, providing thus an evidence of phase transformation which can be correlated with the transition from crystal to liquid-crystal state. Similar behavior was observed for two other bands: the band at $1513 \mathrm{~cm}^{-1}$ with a side-band at $1501 \mathrm{~cm}^{-1}$ related to CC stretching and CCH bending (Fig. 8 - right panel) and the band at $1269 \mathrm{~cm}^{-1}$ with a side-band at $1255 \mathrm{~cm}^{-1}$ related to CC and CN stretching and CCH bending (Fig. 8 - left panel). Above about $95{ }^{\circ} \mathrm{C}$ the components of the first doublet are seen at 1508 and $1498 \mathrm{~cm}^{-1}$, while the second doublet transforms into a single band at about $1261 \mathrm{~cm}^{-1}$. For these spectral features the integral intensities were calculated in the similar way as described above, and analogous temperature dependence was found (Fig. 9a - upper panel). No abrupt change in the band intensities or frequencies could have been detected at the liquid crystal to isotropic phase transition. This indicates that the conformation of the molecule is more affected at the crystal to liquid crystal phase transition than at the liquid crystal to isotropic phase transition. 
On the other hand, on temperature increasing other spectral features e.g. at 1139 and $1469 \mathrm{~cm}^{-1}$ (at $24{ }^{\circ} \mathrm{C}$ ) do not show any important modifications: the only visible change is a slight shift towards lower frequencies (1135 and $1467 \mathrm{~cm}^{-1}$ at about $90{ }^{\circ} \mathrm{C}$ ), simultaneously their intensity continuously decreases (Fig. 9a - lower panel).
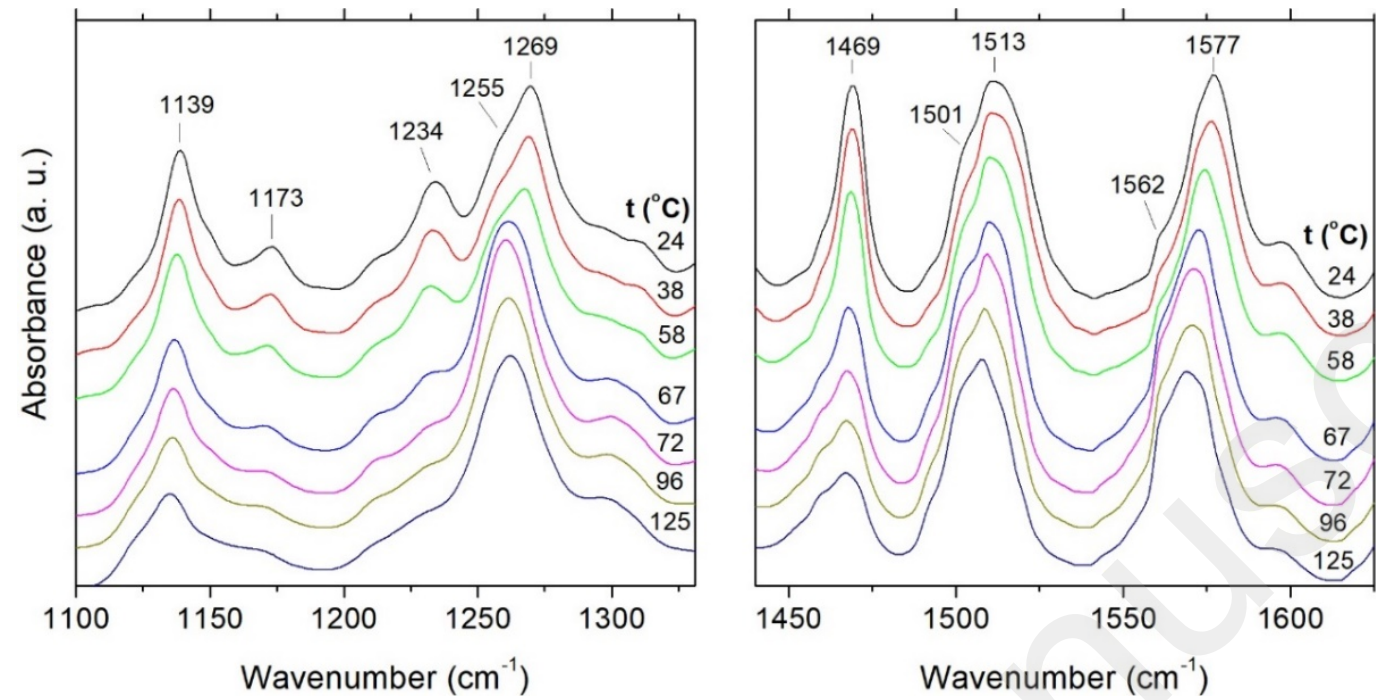

Figure 8. Temperature dependence of the IR absorption spectra of BPM-3,4-C16. Note that for clarity the spectra are separated along the absorbance axis.

(a) BPM-3,4-C16

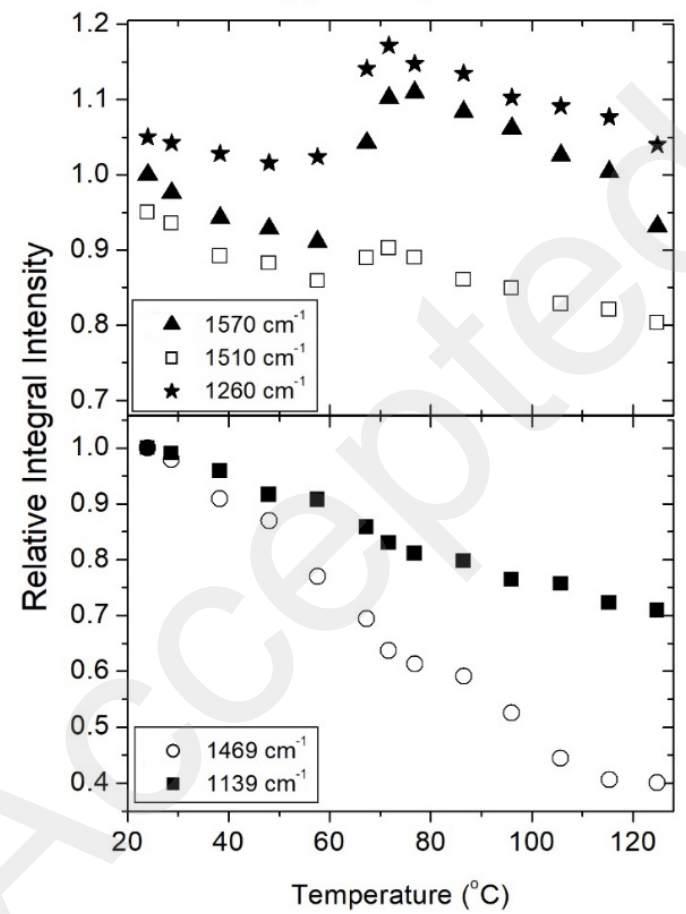

(b) BPM-3,4-C12

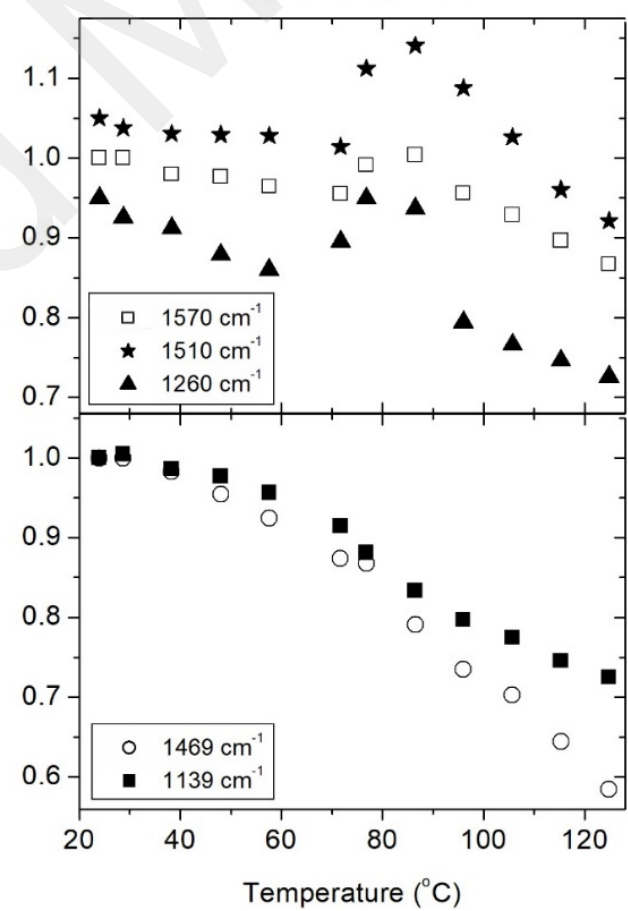

Figure 9. Temperature dependence of the integral intensities of the selected vibrational bands of the BPM-3,4-C16 (a) and BPM-3,4-C12 (b).

Infrared spectra of BPM-3,4-C12 for various temperatures are displayed in Fig. 10. On heating interesting modifications were observed for the following vibrational features: triplet at 
1562, 1570, $1583 \mathrm{~cm}^{-1}$; triplet at 1502, 1509, $1514 \mathrm{~cm}^{-1}$; and doublet at 1255, $1269 \mathrm{~cm}^{-1}$. In Fig. $9 \mathrm{~b}$, we show temperature dependence of the integral intensities of these features. At about 70 ${ }^{\circ} \mathrm{C}$, their integral intensities grow, while for other vibrational bands at 1469 and $1138 \mathrm{~cm}^{-1}$ their intensities decrease continuously without any visible modification due to transition to liquid crystal phase. In conclusion, the temperature behavior of the IR spectra of BPM-3,4-C12 is analogous to that one observed for BPM-3,4-C16.

Taking into account the results of DFT calculations, which indicated bands most sensitive for twisting of the molecule (side bands at 1562, 1501 and $1255 \mathrm{~cm}^{-1}$ ), together with the temperature dependence of the IR spectra, one can suggest that BPM-3,4-C16 and BPM3,4-C12 molecules increase their dihedral angle at the temperature of transition from the crystal to liquid crystal state and the molecules adopt a more twisted cross conformation in the liquid crystalline phase. The intensity of these side bands increases with the dihedral angle.
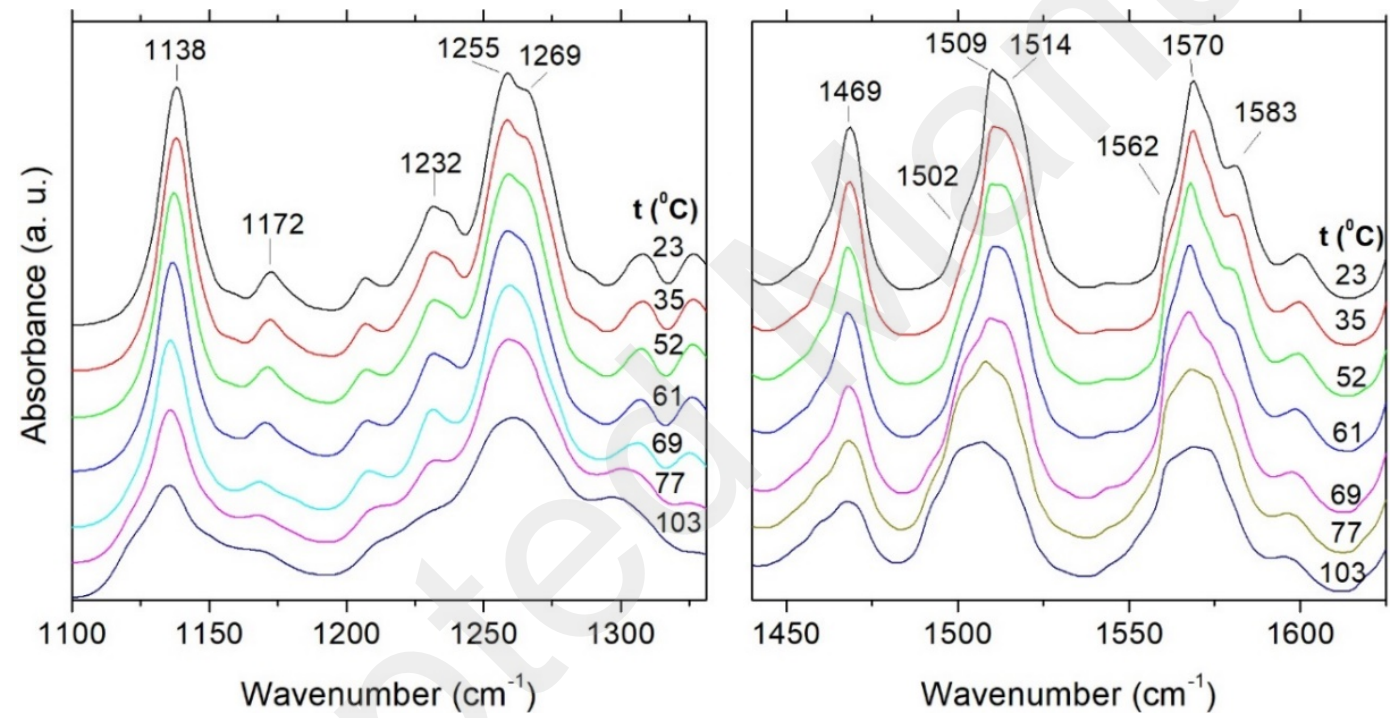

Figure 10. Temperature dependence of the IR absorption spectra of BPM-3,4-C12. Note that for clarity the spectra are separated along the absorbance axis.

\section{(b) Thin film cooling (step 2) and heating (step 3)}

Subsequently, the obtained thin films were cooled down to room temperature and heated up until melting into the isotropic phase again. For BPM-3,4-C16, we have focused our attention on broad vibrational features related to the CN and CC vibrations centered at about 1512 and $1572 \mathrm{~cm}^{-1}$ (Fig. 11 and Table 3). The bands were decomposed into two or three components using Lorentz and/or Gauss functions in order to study their temperature dependences. 
(a) BPM-3,4-C16 cooling

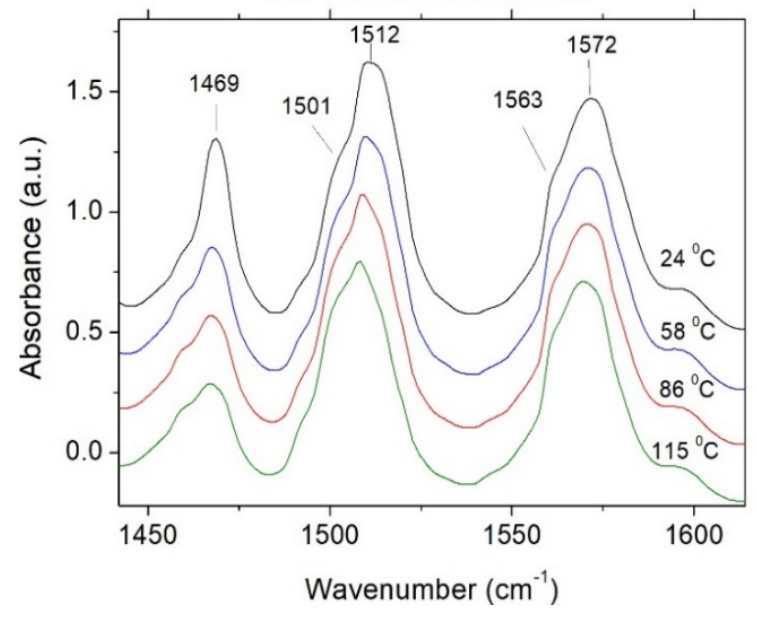

(b) BPM-3,4-C16 heating

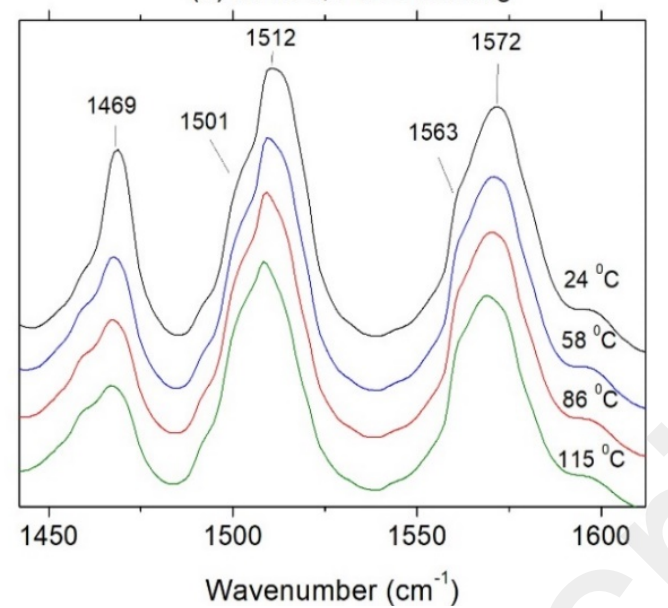

Figure 11. Temperature dependence of the IR absorption spectra of BPM-3,4-C16 thin films on cooling (a) and heating (b). Note that for clarity the spectra a separated along the absorbance axis.

In the BPM-3,4-C16 spectrum, on the low-frequency side of the broad spectral feature centered at $1512 \mathrm{~cm}^{-1}$ (CC stretching and CCH bending) one can see a side-band at $1501 \mathrm{~cm}^{-1}$, which appreciably increases its intensity on heating, while the intensity of the main band continuously decreases (Fig. 11b). There is nearly no difference between cooling and heating. Moreover, we found no visible band changes at the phase transition temperatures, i.e. transitions from crystal to liquid crystal and liquid crystal to isotropic liquid. We propose that the band at $1501 \mathrm{~cm}^{-1}$ is with a spectral feature at $1551 \mathrm{~cm}^{-1}$ in calculated spectra of BPM-3,4-C1 which is sensitive for the twisting of molecule (Fig. 6). Similarly, for the vibrational feature $1572 \mathrm{~cm}^{-1}$ we find analogous temperature dependence: on heating the side-band at $1563 \mathrm{~cm}^{-1}$ grows and the main-band at $1572 \mathrm{~cm}^{-1}$ decreases its intensity. As seen in Fig. 6, this band only increases its frequency on twisting and it has no side-band. However, the calculations were performed for the simplified molecule, therefore it is possible that the observed temperature effect is also due to the twisting of molecule. It should be emphasized that the observed changes are slightly sample dependent. Nevertheless for each sample, we always observed the intensity increase of the side-band and decrease of the main-band upon heating. 
(a) BPM-3,4-C16

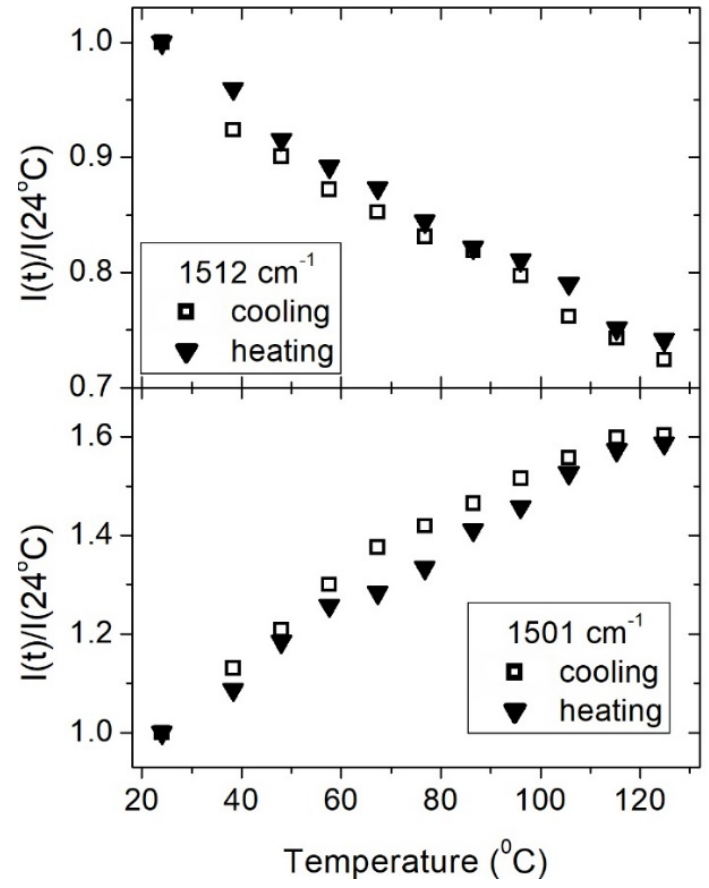

(b) BPM-3,4-C16

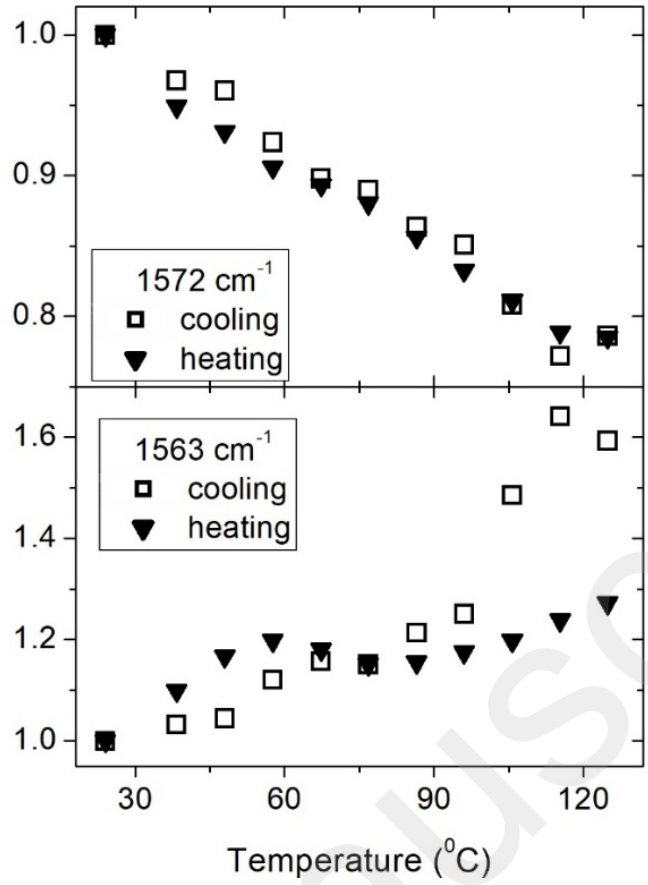

Figure 12. Temperature dependence of the integral intensities of spectral bands for thin layer of BPM-3,4-C16 on cooling and heating: (a) side-band at $1501 \mathrm{~cm}^{-1}$ and main-band at 1512 $\mathrm{cm}^{-1}$ and (b) side-band at $1563 \mathrm{~cm}^{-1}$ and main-band at $1572 \mathrm{~cm}^{-1}$.

For the IR spectra of BPM-3,4-C12 thin films, analogous modifications on cooling and heating were observed, as described above for BPM-3,4-C16. In Fig. 13, we see similar mainbands at 1512 and $1573 \mathrm{~cm}^{-1}$ with side-bands at 1501 and $1563 \mathrm{~cm}^{-1}$, respectively. Their temperature dependences are displayed in Fig. 14. It is to be stressed that the intensity increase of the side-band $1563 \mathrm{~cm}^{-1}$ is not very pronounced, nevertheless in contradiction to the mainband at $1573 \mathrm{~cm}^{-1}$ its intensity does not decrease. It is to be stressed that these dependences are also slightly sample dependent, however for all studied samples the side-band intensities always increased (eventually were nearly the same) when temperature was increasing. 
(a) BPM-3,4-C12 cooling

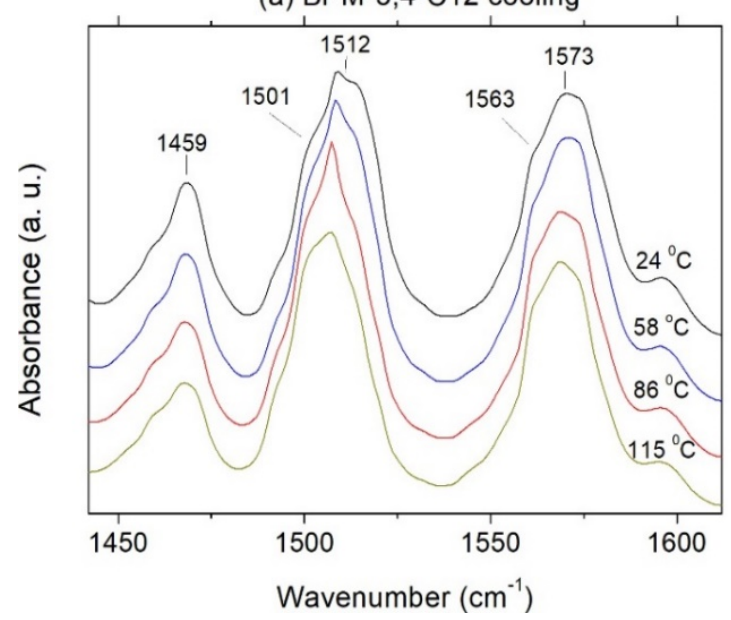

(b) BPM-3,4-C12 heating

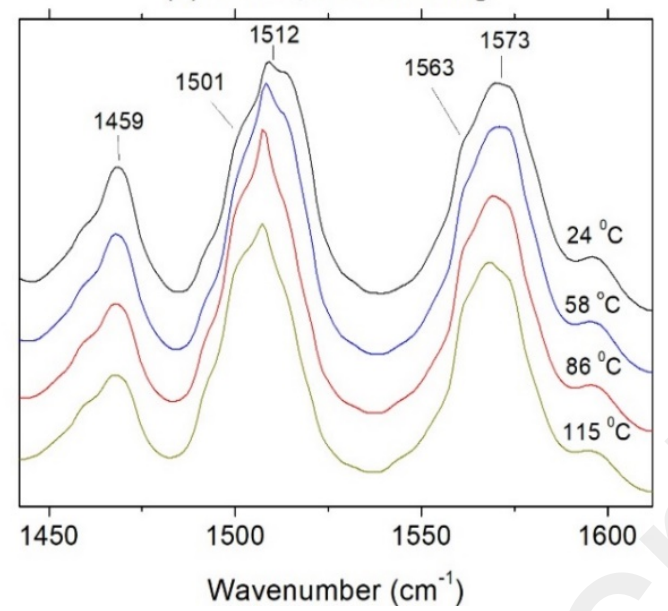

Figure 13. Temperature dependence of the IR absorption spectra of thin films of BPM-3,4-C12 on cooling (a) and heating (b). Note that for clarity the spectra are separated along the absorbance axis.

(a) BPM-3,4-C12

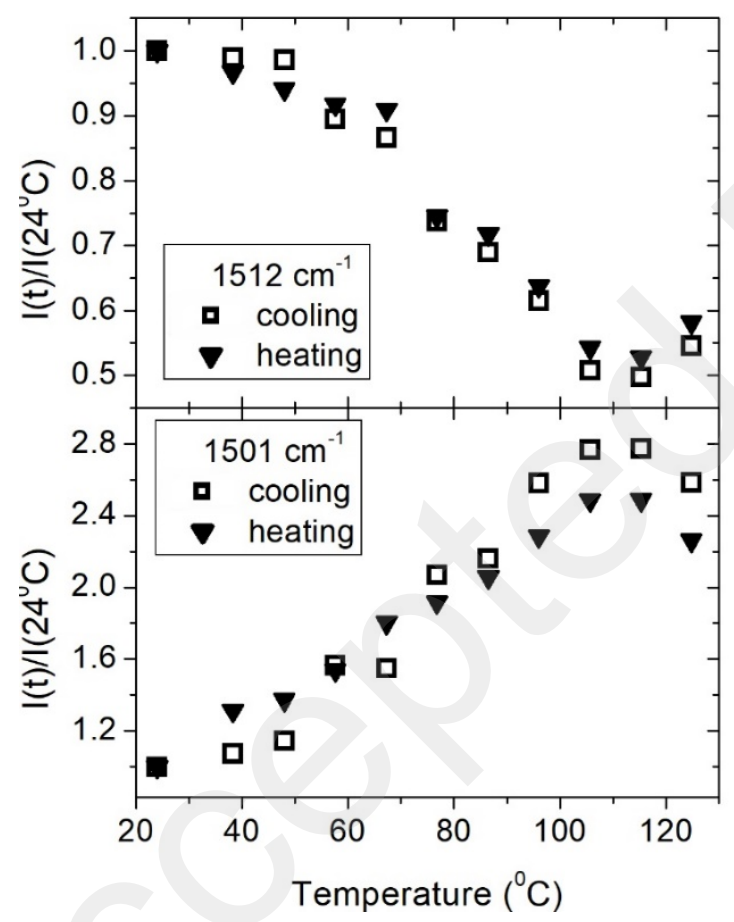

(b) BPM-3,4-C12

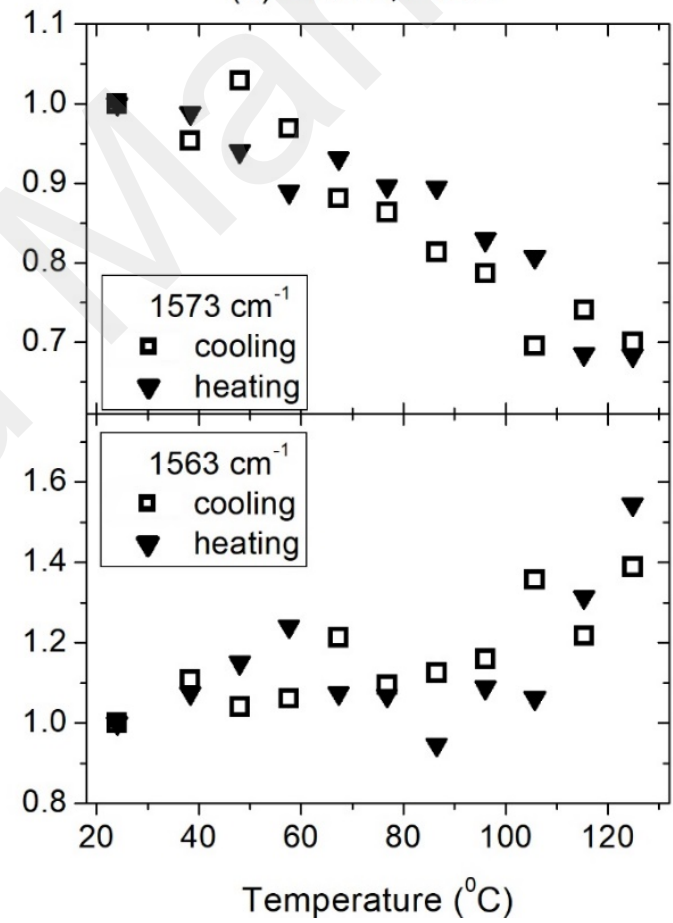

Figure 14. Temperature dependence of the integral intensity of the spectral features for thin layer of BPM-3,4-C12 on cooling and heating: (a) side-band at $1501 \mathrm{~cm}^{-1}$ and main band at $1512 \mathrm{~cm}^{-1}$ and (b) side-band at $1563 \mathrm{~cm}^{-1}$ and main band at $1573 \mathrm{~cm}^{-1}$.

\section{Conclusion}

To summarize, for both compounds the vibrational feature centered at about $1512 \mathrm{~cm}^{-1}$, assigned to CC stretching and CCH bending vibrations, contains a component at about 1501 
$\mathrm{cm}^{-1}$ which substantially increases its intensity on sample heating. Similar behavior, though not so pronounced, is observed for the band at $1573 \mathrm{~cm}^{-1}$ with the side-band at $1563 \mathrm{~cm}^{-1}$ (CN and CC stretching). Taking into account the results of our DFT calculations, one can suggest that the temperature increase of the side-band at $1501 \mathrm{~cm}^{-1}$ is related to increase of the dihedral angle, i.e. twisting of molecules. It is also possible that similar effect (though not so pronounced), observed for the side-band at $1563 \mathrm{~cm}^{-1}$, is also due to the twisting of molecules. Thus, the dihedral angle in the liquid crystalline phase is higher than the one in the crystalline phase (i.e. increase of the side-bands), meaning that, in any case, the molecule is not flat in the columnar liquid crystalline phases. This supports the packing model which has been previously proposed in which the molecules adopts a twisted cross conformation and are interdigitated alternatively along their long axis and their short axis to form the columns.

\section{ORCID}

R. Świetlik http://orcid.org/000

F. Camerel

\section{References}

[1] Lehn JM, Supramolecular Chemistry; Wiley-VCH: New-York 1995.

[2] Collings PJ, Hird M, Introduction to Liquid Crystals: Chemistry and Physics, USA, Taylor and Francis, London 1997.

[3] Wöhrle T, Wurzbach I, Kirres J, Kostidou A, Kapernaum N, Litterscheidt J, Haenle JC, Staffeld P, Baro A, Giesselmann F, Laschat S. Discotic Liquid Crystals. Chem Rev. 2016; 116: 1139-1241.

[4] Campidelli S, Lenoble J, Barberá J, Paolucci F, Marcaccio M, Paolucci D, Deschenaux R. Supramolecular Fullerene Materials: Dendritic Liquid-Crystalline Fulleropyrrolidines. Macromolecules 2005; 38:7915-7925.

[5] Dardel B, Guillon D, Heinrich B, Deschenaux R. Fullerene-containing liquid-crystalline dendrimers. J Mater Chem. 2001; 11: 2814-2831.

[6] Terazzi E, Bourgogne C, Welter R, Gallani JL, Guillon D, Rogez G, Donnio B. SingleMolecule Magnets with Mesomorphic Lamellar Ordering. Angew Chem. 2008; 120: 500-505.

[7] Huitorel B, Benito Q, Fargues A, Garcia A, Gacoin T, Boilot JP, Perruchas S, Camerel F. Mechanochromic Luminescence and Liquid Crystallinity of Molecular Copper Clusters. Chem Mater. 2016; 28: 8190-8200.

[8] Thiery S, Heinrich B, Donnio B, Poriel C, Camerel F. Luminescence modulation in liquid crystalline phases containing a dispiro[fluorene-9,11'-indeno[1,2-b]fluorene-12',9"fluorene] core. J Mater Chem C. 2014; 2: 4265-4275.

[9] Thiery S, Heinrich B, Donnio B, Poriel C, Camerel F. Modulation of the Electronic and Mesomorphic Properties of Alkynyl-Spirobifluorene Compounds as a Function of the Substitution Pattern, J Phys Chem C. 2015; 119: 10564-10575.

[10] Akdas-Kilig H, Godfroy M, Fillaut JL, Donnio B, Heinrich B, Kędziora P, Malval JP, Spangenberg A, van Cleuvenbergen S, Clays K, and Camerel F. Mesogenic, 
Luminescence, and Nonlinear Optical Properties of New Bipyrimidine-Based

Multifunctional Octupoles. J Phys Chem C. 2015;119:3697-3710.

[11] Van Cleuvenbergen S, Kędziora P, Fillaut JL, Verbiest T, Clays K, Akdas-Kilig H, Camerel F, Chiral Side Groups Trigger Second Harmonic Generation Activity in 3D Octupolar Bipyrimidine-Based Organic Liquid Crystals. Angew Chem Int Ed. 2017;56:9546-9550.

[12] Gaussian 03, Revision D.01, Frisch MJ, Trucks G, W, Schlegel HB, Scuseria GE, Robb MA, Cheeseman JR, Montgomery Jr JA, Vreven T, Kudin KN, Burant JC, Millam JM, Iyengar SS, Tomasi J, Barone V, Mennucci B, Cossi M, Scalmani G, Rega N, Petersson GA, Nakatsuji H, Hada M, Ehara M, Toyota K, Fukuda R, Hasegawa J, Ishida M, Nakajima T, Honda Y, Kitao O, Nakai H, Klene M, Li X, Knox JE, Hratchian HP, Cross JB, Bakken V, Adamo C, Jaramillo J, Gomperts R, Stratmann RE, Yazyev O, Austin AJ, Cammi R, Pomelli C, Ochterski JW, Ayala PY, Morokuma K, Voth GA, Salvador P, Dannenberg JJ, Zakrzewski VG, Dapprich S, Daniels AD, Strain MC, Farkas O, Malick DK, Rabuck AD, Raghavachari K, Foresman JB, Ortiz JV, Cui Q, Baboul AG, Clifford S, Cioslowski J, Stefanov BB, Liu G, Liashenko A, Piskorz P, Komaromi I, Martin RL, Fox DJ, Keith T, Al-Laham MA, Peng CY, Nanayakkara A, Challacombe M, Gill PMW, Johnson B, Chen W, Wong MW, Gonzalez C, and Pople JA. Gaussian, Inc., Wallingford CT, 2004.

[13] Akdas-Kilig H, Roisnel T, Ledoux I, Le Bozec H. A new class of bipyrimidine-based octupolar chromophores: synthesis, fluorescent and quadratic nonlinear optical properties. New J Chem. 2009;33: 1470-1473.

[14] Barszcz B, Kędzierski K, Jeong HY, Kim T-D. Spectroscopic properties of diketopyrrolopyrrole derivatives with long alkyl chains. J Lumin. 2017;185:219-227.

[15] Scott AP, Radom L. Harmonic Vibrational Frequencies: An Evaluation of Hartree-Fock, Møller-Plesset, Quadratic Configuration Interaction, Density Functional Theory, and Semiempirical Scale Factors. J Phys Chem. 1996;100:16502-16513.

\section{References suggested by the referee}

[ ] Sahamir SR, Said SM, Sabri MFM, Mahmood MS, Bin Kamarudin MA and Moutanabbir O., Studies on relation between columnar order and electrical conductivity in HAT6 discotic liquid crystals using temperature-dependent Raman spectroscopy and DFT calculations. Liq Crys. 2018; 45:522-535.

[ ] Gowda A, Kumar M and Kumar S. Discotic liquid crystals derived from polycyclic aromatic cores: from the smallest benzene to the utmost graphene cores. Liq Cryst. 2017; 44: 1990-2017.

[ ] Cammidge AN, Turner RJ, Beskeni RD and Almutairi T, A modified route to unsymmetrically substituted triphenylenes, new functionalised derivatives and twins, and the smallest reported triphenylene mesogen. Liq Cryst. 2017; 44: 2018-2028.

[ ] Roth S and Lehmann M. Mesogenic origami - four-armed, star-shaped mesogens as precursors for functional liquid crystal materials. Liq Cryst. 2017; 44: 1830-1851. 
